\title{
On Coins, Parallel Universes and the Cooperation and Verification Mechanism
}

In the novel Northern Lights, Philip Pullman writes: "If a coin comes down heads, that means that the possibility of its coming down tails has collapsed. Until that moment the two possibilities were equal. But on another world, it does come down tails. And when that happens, the two worlds split apart." While this is a quote from fiction, it describes the disaster with the Cooperation and Verification Mechanism (CVM) quite well.

The European Commission seems to inhabit a universe which is too distant from the realities of Bulgaria and Romania, which are the only EU members subjected to the CVM. Even worse, it is currently attempting to sweep the CVM under the carpet of oblivion for no good reason, as seen in Commissioner Vera Jourova's presentation on the mechanism before the LIBE Committee at the European Parliament on 10 September 2020. The Commission is attempting to persuade concerned citizens and Members of the European Parliament (MEPs) that it would continue the monitoring of these countries under the new Rule of Law Mechanism. It insists that this be an argument to terminate the CVM, but is this justified? When did the possibility of having an objective CVM collapse?

\section{A Tale of Two Parallel Universes}

It is no secret that admitting a country in the EU is primarily a political decision despite the notion of conditionality which allegedly transformed the accession process into politico-legal. When admitting Bulgaria and Romania, however, EU institutions were cautious despite the political consensus. Bulgaria and Romania were decoupled from the other candidates in the fifth wave of enlargement, so they joined the EU in 2007 unlike the rest which joined in 2004. In addition, their accession treaty saw unprecedented safeguard clauses. One of them even allowed the EU to defer accession if the countries were "manifestly unprepared to meet the requirements of membership" in the EU. The Commission was so worried that this might have been the case that it subjected the countries to monitoring and set benchmarks for them which became the basis of the CVM. For Bulgaria, they are six: judicial independence, legal framework, continued judicial reform, highlevel corruption, general corruption, and organized crime. Following accession, the Commission decided not to invoke the safeguard clauses, but recognized that monitoring would be needed for "some time".

On this very forum, I have heavily criticized the 2018 CVM report which declared three of the benchmarks closed for Bulgaria (judicial independence, legal framework 
and organized crime) as well as the 2019 CVM report which recommended that the mechanism be lifted for Bulgaria. Among the many reasons why these conclusions can be challenged are a series of public statements by the judiciary, including by the President of the Supreme Court of Cassation Lozan Panov, complaining from political abuse. In fact, in an interview in September 2020 for Spiegel, Panov said he had sent tens of written complaints against harassment of the judiciary to the Commission which have been ignored. Bulgaria is continuously shaken by corruption scandals involving Prime Minister Borissov and his political allies. Legislation undermining human rights is enacted - Bulgaria even manages to deprive EU Directives from their purpose. Neither of the serious longstanding issues of Bulgaria's justice system seem to have been solved - the politicization of the Supreme Judicial Council, the Prosecutor's Office which overshadows the courts, etc.

If one takes a closer look at the CVM reports, however, one may also see that the conclusions are far from being the only problem. Many of the recommendations by the Commission either seem ludicrous from a legal perspective or show a level of naiveté which one does not expect from an EU institution. To provide a few examples:

- Since Kolevi v. Bulgaria, which exposed one of the biggest threats to the rule of law in Bulgaria - the General Prosecutor who has excessive powers but bears no liability for his actions or omissions because there are no mechanisms to keep him accountable - Bulgaria has been playing a cat-and-mouse game with the Council of Europe and the Venice Commission for 10 years, attempting desperately to avoid reform. While the Commission recognized the seriousness of this decision, in the 2012 CVM report it recommended that the General Prosecutor, who was supposed to be elected the following year, reformed the prosecution in structure and organization himself with the help of experts (at page 20). It is certainly bizarre that the Commission assumed that a person with excessive powers would be willing to reduce them, but even further Bulgaria is a parliamentary republic and such reforms should be implemented by Parliament.

- The fate of the Yaneva Gate scandal which shook Bulgaria in 2015 is also quite revealing. It concerned leaked conversations between two senior judges who discussed how Prime Minister Boyko Borissov, General Prosecutor Sotir Tsatsarov and other politicians instructed them how to decide cases, how judges were not promoted based on merit but based on "dangerous liaisons" with politicians, etc. The 2016 CVM report recognized the scandal and recommended that Bulgaria provide "conditions for an impartial investigation" of these allegations. One may ponder if a government would have an interest in investigating circumstances which can incriminate the Prime Minister. One may also wonder how realistic this recommendation is in light of Kolevi because the General Prosecutor would not have an interest in investigating himself either. Even though the scandal was not investigated, the Commission was not too troubled in subsequent reports. 


\section{How MEPs Attempted to Flip the Coin}

Bulgarian citizens have been protesting for more than two months demanding the resignation of the third government of Boyko Borissov and General Prosecutor Ivan Geshev. While since the beginning of 2020 Bulgaria has been torn by corruption scandals involving Boyko Borissov, the raid against Bulgaria's Presidency by the Prosecutor's Office was the last feather which broke the camel's back. Not only did it demonstrate a violation of Bulgaria's Constitution for the President benefits from immunity, but it raised serious suspicions for lack of separation of powers. On the one hand, Borissov's ties with Ivan Geshev are well-known, as evidenced by a leaked recording in which Borissov gives instructions who should be charged. On the other hand, President Rumen Radev is a vocal critic of Borissov.

While the European Commission has remained silent and its spokespeople change facial colors when asked about Bulgaria's protests at press briefings, some MEPs have taken an interest in Bulgaria's decaying rule of law. On 10 September 2020, Commissioner Vera Jourova was invited to speak before the LIBE Committee of the European Parliament regarding the CVM. Jourova gave an upbeat speech in which she stressed how much the Commission had achieved with the CVM. She also contended that the CVM was always meant to be temporary - considering the new Rule of Law Mechanism, maybe it was time to terminate it.

Some MEPs, especially those not from the European People's Party (EPP), were not as optimistic as Jourova. Ramona Strugariu (Renew) expressed concerns about the state of Bulgaria's rule of law and the excessive violence which Bulgaria's government has used against protesting citizens, including women and children, and journalists who were beaten, gassed, threatened and arrested for doing their job covering the protests. Tineke Strik (Greens) had questions regarding the excessive powers of the Prosecutor's Office. Elena Yoncheva (Socialists) told Mrs. Jourova that it was high time for the Commission to make a choice regarding what it valued more: democracy or Mr. Borissov. The most fervent criticism came from Clare Daly (Socialists) who argued that the Commission's observations did not match Bulgarian reality and stated that if the Commission saw progress, she could only conclude it was "grossly incompetent" or "subservient to Borissov's interests" because of his connections to powerful EU parties.

\section{Which Side of the Coin Do You See?}

Vera Jourova's response to the criticism by MEPs merits some dissection:

On feelings: The Commissioner stressed that the time allocated to her to respond was not sufficient to "explain everything and to get upset also". She emphasized she had feelings and she contended that she strongly rejected "the accusation [she was] an accomplice of Mr. Borissov" because she was doing her job "with full honesty and objectivity". She asked "not to be offended" like this. The hundreds of thousands of Bulgarians protesting on the streets have bitter feelings too - some protested in front of the Commission's office in Sofia, asking if the EU was blind. 
Diverse international media are ringing the alarm that something is rotten in Bulgaria and in the Commission. Politico overtly refers to Bulgaria as a "mafia state". Malta Today asked if we were part of the "wrong Union" having in mind the dual standard vis-à-vis the rule of law. Judges subjected to harassment such as the President of the Supreme Court Lozan Panov also have feelings - Panov asked the EU not to be blind and silent because "the most important parts of the Bulgarian judiciary [were] politically influenced and corruptible". Every coin has two sides, but unless one lives in a parallel universe, one cannot see a success story in Bulgaria.

On legitimacy: Instead of responding to the criticism by the MEPs in substance, Commissioner Jourova dedicated a lot of time to discussing the new Rule of Law mechanism and how it was going to be "a preventative, standardized and predictable tool". We are yet to see the first reports under the new mechanism, but Bulgaria's case raises serious concerns whether the Commission is in a position to apply an objective standard. If many consider the CVM to be a failure and if the Commission stubbornly refuses to admit it might have made a mistake, then the legitimacy of the Commission is threatened. One may also doubt if the Commission is capable of preventing rule of law crises in light of concerns it might have contributed to one. From this standpoint, the Commission's silence regarding the mass protests against the corruption of Borissov and the Prosecutor's Office seems guilty. Jourova's attempt to get out of Strugariu's question with grace by stating that she supported the right to protest was not persuasive, considering this right is derived from the fundamental rights to public opinion and gatherings. Citizens expect a public stance on corruption and rule of law decay, not a reminder of the rights they are aware of anyway.

On sweeping the CVM under the carpet: Commissioner Jourova's argument that the CVM was meant to be temporary and that monitoring would continue under the new mechanism seems to forget the origin of the CVM. Bulgaria and Romania accessed the Union even though they did not fulfill the criteria for accession. The purpose of the CVM was to help them catch up. If that is not the case, it seems illogical to terminate the mechanism. Furthermore, as Jourova argues the new monitoring is "standardized", it is difficult to comprehend how the outstanding work remaining under the CVM would continue under the new mechanism - Jourova at least recognized there remained work to be done in Bulgaria. We have no certainty how efficient the new mechanism will be. Moreover, the CVM is so technical and specific that if the Commission transfers the remaining work under the new Rule of Law mechanism, this will automatically mean the new mechanism will neither be standardized nor preventative.

\section{Can Parallel Universes Collide?}

The question of whether parallel universes can collide has occupied the minds of fiction aficionados. It is known there might be bruises or even disaster when that occurs. My conclusions are thus negative - it seems the coin has come down heads for the Commission and this is the side it likes. The reasons for this seem purely political - Borissov benefits from the support of the EPP which dominates the EU political scene. On an EU level, we can only hope that vigilant MEPs will continue 
denouncing the Commission's dual standards regarding Bulgaria. From a Bulgarian perspective, the Commission's complicity with Borissov's regime is even more visible and the feelings of a Commissioner will not blur the view. Even worse - anger against the Commission may soar. 